\title{
Erratum to: Offishore Platform Integration and Floatover Technology
}

\author{
Gengshen Liu and Huajun Li
}

\section{Erratum to:}

\section{G. Liu and H. Li, Offshore Platform Integration}

and Floatover Technology, Springer Tracts in Civil Engineering, DOI 10.1007/978-981-10-3617-0

The original version of the book was inadvertently published without updating the additional corrections such as tense change, insertion of articles, hyphenation change, spacing error, figure corrections and placement of figures. The erratum book has been updated with the changes.

The updated online version of this book can be found at http://dx.doi.org/10.1007/978-981-10-3617-0 